\title{
Computed Tomography-Based Feasibility Study of C1 Posterior Arch Crisscrossing Screw Fixation
}

\author{
Gururaj Sangondimath, Abhinandan Reddy Mallepally, Suman Salimath \\ Department of Spine Services, Indian Spinal Injuries Centre, New Delhi, India
}

\begin{abstract}
Study Design: Retrospective radiographic analysis.
Purpose: Posterior fixation of $\mathrm{C} 1$ using screws is the most popular technique among the various methods for $\mathrm{C} 1$ stabilization, but it places the surrounding neurovascular structures at risk. Approximately $20 \%$ of the population has an anomalous groove for the vertebral artery; therefore, salvage methods are necessary. Therefore, we analyzed the feasibility of a newer $\mathrm{C} 1$ posterior arch crisscrossing screw fixation technique and studied its feasibility in the Indian population on the basis of the anatomy of the $\mathrm{C} 1$ posterior arch. Overview of Literature: Multiple techniques have been described for C1-C2 fixation, such as wiring techniques, interlaminar clamps, transarticular screws, screw-plate/screw-rod system fixation, and hook-screw system fixation techniques, to provide rigid C1-C2 stability. However, although C1 fixation has evolved with time, it is not complication-free.

Methods: A 100 computed tomography (CT) scans of cervical spines with $1 \mathrm{~mm}$ slice thickness in the axial and sagittal sections obtained were randomly selected for the evaluation. Atlantoaxial anomalies due to trauma, deformities, infections, and tumors were excluded. All the images were measured for height of the posterior tubercle, width of the posterior arch, and length of the screw, and the screw projection angle was calculated. Demographic data were collected for all the subjects.

Results: Out of the 88 CT scans analyzed, the mean height of the posterior tubercle was $7.4 \mathrm{~mm}$, wherein $84.09 \%$ exceeded $7 \mathrm{~mm}$, and the width of the posterior tubercle was $5.4 \mathrm{~mm}$, wherein $88.6 \%$ (n=78) had posterior arch width $>3.5 \mathrm{~mm}$. A total of 13.6\% (n=12) vertebrae were not suitable for screw placement, whereas $75 \%(n=66)$ vertebrae could accommodate $3.5 \times 15 \mathrm{~mm}$ or longer screws. The screw projection angles ranged from $11.2^{\circ}$ to $35^{\circ}$ on the right and from $15.6^{\circ}$ to $38.2^{\circ}$ on the left.

Conclusions: $\mathrm{C} 1$ posterior arch screw fixation is a feasible and safe method because it poses little risk of injury to the surrounding neurovascular structures.
\end{abstract}

Keywords: C1 posterior arch; Vertebral artery; Complications; Crisscrossing

\section{Introduction}

The occipital-atlantoaxial complex comprising $\mathrm{C} 0-\mathrm{C} 1$ (atlanto-occipital complex) and C1-C2 (atlantoaxial complex) articulations plays a unique role with important functions such as providing cervical flexion-extension, bending, and rotation. $\mathrm{C} 1-\mathrm{C} 2$ articulation lacks a disc in between, and their stability mainly relies on the articular and osseous structures along with the surrounding ligaments [1,2]. Etiologies such as trauma, inflammatory diseases, tumors, or congenital malformations lead to damage of these vital elements and cause instability, which

Received Jun 20, 2019; Revised Jul 16, 2019; Accepted Aug 19, 2019

Corresponding author: Abhinandan Reddy Mallepally

Department of Spine Services, Indian Spinal Injuries Centre, Vasant Kunj, Sector C, New Delhi, Delhi 110070, India

Tel: +91-11-42255356,+91-8686598876, Fax: +91-11-26898810, E-mail: mabhi28@gmail.com 
may result in local pain, motor disability, and even death, often necessitating surgical intervention for realignment fixation and decompression [3].

Multiple techniques have been described for $\mathrm{C} 1-\mathrm{C} 2$ fixation. Posterior fixation techniques were widely used to provide rigid $\mathrm{C} 1-\mathrm{C} 2$ stability, including wiring, Brooks and Jenkins [4] and Gallie [5] techniques, interlaminar clamps, Magerl atlantoaxial transarticular (TA) screws [6], screw-plate system fixation, screw-rod system fixation (Harms and Melcher [7] technique and Goels and Laheri [8] technique), and hook-screw system fixation [9]. At present, screw fixation has replaced wires or hooks to provide greater rigidity and prevent most postoperative movement [10]. An added advantage of the screw fixation technique is the immediate stability obtained, obviating the need for halo vest immobilization.

Posterior fixation of $\mathrm{C} 1$ using screws is the most popular technique among the various methods for $\mathrm{C} 1$ stabilization [11]. However, it places the surrounding neurovascular structures such as the vertebral artery (VA), C2 nerve root, and internal carotid artery, spinal cord, and hypoglossal nerve at grave risk, resulting in troublesome bleeding and even cerebral infarction [12]. Also, approximately $20 \%$ of the population has an anomalous groove for the VA in the C2 pars interarticularis on at least one side, which places the VA in the direct path of a C1-C2 TA screw [3]. Although C1 fixation has evolved with time, it is not a complication-free procedure. Salvage methods are necessary when there is anatomical variation, traumatic or iatrogenic damage, or suspected VA injury. Thus, we analyzed the feasibility of a newer $\mathrm{C} 1$ posterior arch crisscrossing screw fixation technique and studied its feasibility in the Indian population on the basis of the anatomy of the $\mathrm{C} 1$ posterior arch.

\section{Materials and Methods}

\section{Radiological evaluation of $\mathrm{C} 1$ arch anatomy}

A 100 computed tomography (CT) scans of cervical spines with $1 \mathrm{~mm}$ slice thickness in the axial and sagittal sections obtained at Indian Spinal Injuries Centre were randomly selected for evaluation. Informed consent was obtained from all individual participants included in the study. Institutional review board approval was taken for the present study (IRB approval no., ISIC/RP/2019/048). Images obtained in the supine position with the scan image

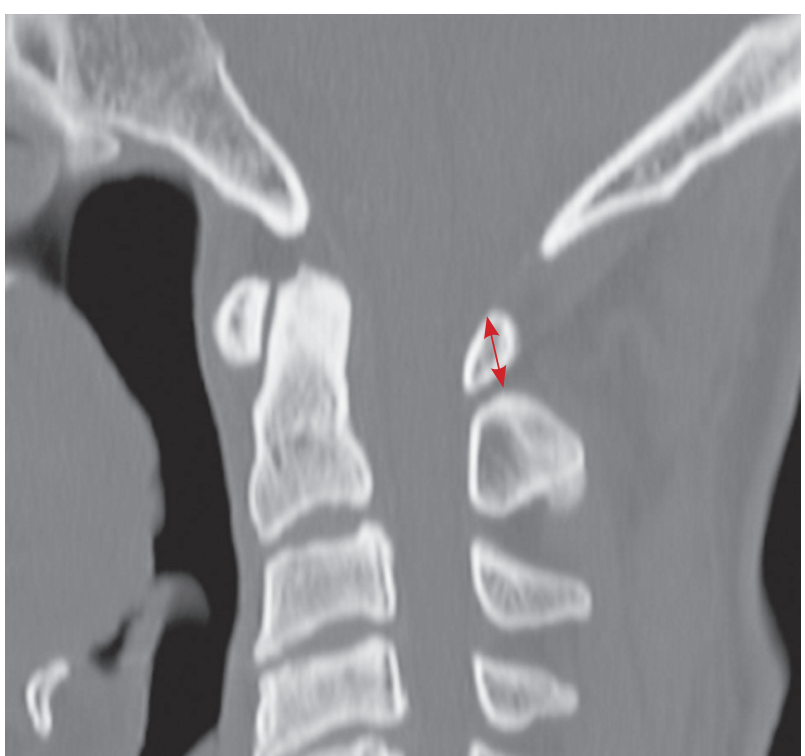

Fig. 1. The red arrow shows the height of the posterior tubercle in the mid-sagittal section of computed tomography of the cervical spine.

alignment parallel to the posterior $\mathrm{C} 1$ arch were selected. Criterion for inclusion was scan image alignment parallel to the posterior $\mathrm{C} 1 \mathrm{arch}$. Twelve of the scans not suitable for analysis because of the quality of the CT scan were excluded. Atlantoaxial articulation anomalies due to trauma, deformities, infections, and tumors were also excluded from the study. All the images were measured using the picture archiving communication system by two independent surgeons (G.S. and M.A.). The height of the posterior tubercle on the sagittal plane through the middle plane was measured (Fig. 1). The width of the posterior arch was measured in the following three parts: (1) at the posterior tubercle; (2) just medial to the VA groove, where the arch transforms into the VA groove; and (3) at the middle part between the posterior tubercle and the medial of the VA groove (Fig. 2). The length of the screw from the entry point to the interior VA groove was recorded (Fig. 2), and the screw projection angle was calculated as the angle of the screw on the horizontal plane as described by Jin et al. [3]. Demographic data were collected for all the subjects. The average and standard deviation were calculated to evaluate whether the routinely used 3.5-mm-diameter screws could be placed in a crossed manner in the posterior arch of the atlas as well as to determine the length and angle of the screws.

The technique for the posterior arch screw (PAS) placement involves exposure of the dorsal part of the posterior arch and then identification of the entry points approximately $2 \mathrm{~mm}$ from the posterior tubercle on the opposite 


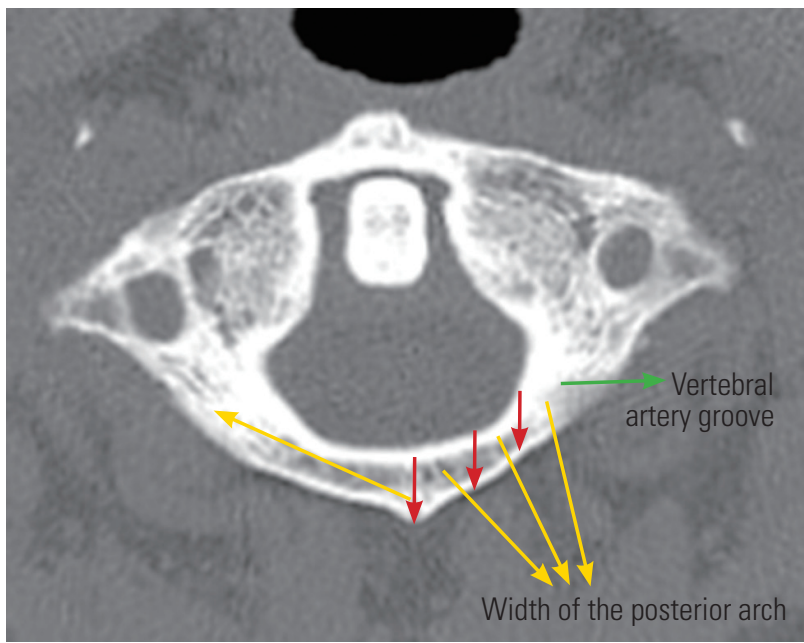

Fig. 2. Red colored arrows on the right side arch show the width of the posterior arch; part 1, medial of the VA groove, where the arch transforms into the VA groove; part 2, middle part between the posterior arch and medial of the VA; part 3, posterior tubercle. On the left side, the yellow arrow shows the screw length. VA, vertebral artery.

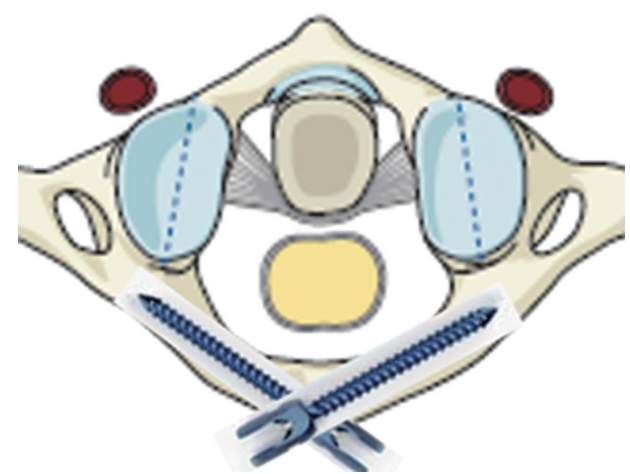

Fig. 3. Pictorial representation of the crisscrossing posterior arch screws.

side. The lower one is $1 \mathrm{~mm}$ below the middle part of the posterior tubercle and parallel to the inferior rim of the $\mathrm{C} 1 \mathrm{arch}$, and the upper one was $2 \mathrm{~mm}$ higher on the other side to avoid screw interference (Fig. 3).

\section{Interobserver and intraobserver reliability}

The kappa coefficients for intraobserver reliability of the posterior tubercle height, width of the arch, length of the screw, and angle of the screw were 0.85 (95\% confidence interval [CI], 0.74-0.95) and 0.89 (95\% CI, 0.79-0.99), respectively. The kappa coefficients for interobserver reliability were 0.74 (95\% CI, 0.59-22 0.88) and 0.75 (95\% CI, $0.64-0.87)$, respectively, indicating high conformity.

\section{Results}

A total of 88 CT scans were reviewed, of which 56 belonged to males and 32 belonged to females. The average age of the patients was $43.4 \pm 16.2$ years (range, 27.2-60 years). The mean height of the posterior tubercle was $7.4 \pm 0.8 \mathrm{~mm}$ (range, 5-9.3 mm), in which $84.09 \%$ exceeded $7 \mathrm{~mm}$. The average width of the medial part of the VA groove (where the arch transforms into the VA groove) was $5.4 \pm 1 \mathrm{~mm}$ on the right side and $5.8 \pm 1.1 \mathrm{~mm}$ (range, 2.5-8.6 mm) on the left. The width of the middle part of the arch was $4.9 \pm 1 \mathrm{~mm}$ (range, $2.5-7.2 \mathrm{~mm}$ ) on the right side and $5.2 \pm 1.1 \mathrm{~mm}$ (range, $2.3-9.8 \mathrm{~mm}$ ) on the left. The width of the posterior tubercle was $5.4 \pm 1.6 \mathrm{~mm}$ (range, $2.8-11.8 \mathrm{~mm})$, in which $88.6 \%(\mathrm{n}=78)$ had posterior arch width more than $3.5 \mathrm{~mm}$. A total of $13.6 \%(\mathrm{n}=12)$ vertebrae were not suitable for screw placement, as their posterior arch was thinner than $3.5 \mathrm{~mm}$. The length of the screws was $16.9 \pm 1.5 \mathrm{~mm}$ on the right side (range, 13.5-20 $\mathrm{mm}$ ) and $16.7 \pm 2 \mathrm{~mm}$ on the left (range, 13-25.4 mm). A total of $75 \%(n=66)$ vertebrae could accommodate $3.5 \times 15$ $\mathrm{mm}$ or longer screws into their posterior arch. The screw projection angles ranged from $11.2^{\circ}$ to $35^{\circ}$ on the right and from $15.6^{\circ}$ to $38.2^{\circ}$ on the left. The summary of the results is shown in Table 1.

\section{Discussion}

Because the atlantoaxial joint is highly mobile with great range of motion, it requires rigid fixation in order to achieve higher rates of fusion [13]. Technically, easy wiring techniques provide poor bending stability, have risk of failure with nonunion rate of $10 \%-15 \%$, and pose an ever-present risk of injury to the spinal cord. They also often require additional external immobilization [14]. TA screws (Magerl technique), however, offer resistance for bending and rotation but are weaker in flexion-extension [15]. Also, they cannot be used in unreduced C1-C2 subluxations, thoracic hyperkyphosis, cervical hyperlordosis or obesity, and VA anomalies. Literature shows that there is up to $23 \%$ variation in the course of VA [16], which increases the chances of VA injury using this technique.

At present, the C1 lateral mass screw (LMS) fixation, described by Harms and Melcher [7] and Goel and Laheri [8], which uses screw-plate or screw-rod constructs, reduces the risk of VA injury when compared with the TA technique method, which is more popular, and allows for 
Table 1. Summary of results of the study

\begin{tabular}{|c|c|c|c|}
\hline Variable & Mean \pm standard deviation & Min-max & Mode \\
\hline Height of the posterior tubercle (mm) & $7.4 \pm 0.8$ & $5-9.3$ & 7 \\
\hline \multicolumn{4}{|l|}{ Length of the screw $(\mathrm{mm})$} \\
\hline Right & $16.9 \pm 1.5$ & $13.5-20$ & 17.8 \\
\hline Left & $16.7 \pm 2.0$ & $13.0-25.4$ & 16 \\
\hline \multicolumn{4}{|l|}{ Angle of the screw $\left({ }^{\circ}\right)$} \\
\hline Right & $23.9 \pm 5.6$ & $11.2-35$ & 21 \\
\hline Left & $26 \pm 5.3$ & $15.6-38.2$ & 23.2 \\
\hline Width of the posterior tubercle $(\mathrm{mm})$ & $5.4 \pm 1.6$ & $2.8-11.8$ & 5.8 \\
\hline \multicolumn{4}{|l|}{ Width of the posterior arch (mm) } \\
\hline Right & $5.4 \pm 1.0^{\text {a) }}, 4.9 \pm 1.0^{b)}$ & $2.5-8.6^{\mathrm{a})}, 2.5-7.2^{\mathrm{b})}$ & $6^{\mathrm{a})}, 4.9^{\mathrm{bl}}$ \\
\hline Left & $5.8 \pm 1.1^{\mathrm{a})}, 5.2 \pm 1.1^{\mathrm{b})}$ & $3.5-8.5^{\mathrm{al}}, 2.3-9.8^{\mathrm{b})}$ & $6.3^{\mathrm{a})}, 6.6^{\mathrm{b})}$ \\
\hline
\end{tabular}

VA, vertebral artery.

${ }^{\text {a) }}$ Medial of the VA groove where the arch transforms into the VA groove. ${ }^{b}$ Middle part between posterior tubercle and medial of the VA groove.

intraoperative reduction of atlantoaxial subluxation. Biomechanical studies revealed that the stability of the $\mathrm{C} 1-$ C2 pedicle screw fixation technique is equivalent to that of the Magerl technique $[17,18]$, and increased fixation points lead to higher stability [19].

Though the C1 lateral mass and pedicle screws have been improved to reduce the risks of neurovascular injury and are a common method of fixation, it is technically demanding and not complication-free. It is difficult to insert the screw, especially when the lateral mass is obscured by a thick posterior arch, anomalous VA, or large paravertebral venous plexus or when there is a high risk of bleeding from the venous plexus [20]. Failure to recognize anatomical variations in the third segment of VA and screw misplacement may lead to disastrous complications after $\mathrm{C} 1$ screw fixation [11]. It may cause formation of an arteriovenous fistula, occlusion, dissection of the VA, and massive bleeding [21,22], which may cause loss of consciousness and, occasionally, impairments in respiration and cardiovascular stability, secondary medullar or cerebellar infarction, and, rarely, death. C2 neuropathy is a well-known complication after $\mathrm{C} 1$ screw fixation, whether the $\mathrm{C} 2$ root is cut or not [20]. The incidence of complications and the prognosis of the patients may vary with the screw entry point, pathology, surgical method, and experience. Thus, new methods are needed to overcome these complications. The $\mathrm{C} 2$ laminar screw proposed by Wright [23] is a good alternative in clinical practice which provides equivalent acute stability to C1 LMSs and C2 pars screws [24]. These screws pose absolutely no risk of VA injury.

The PAS is a safe alternative when compared with the C1 lateral mass or pedicle screw. This technique lowers the risk of bleeding from the venous plexus and VA injury. Floyd and Grob [25] and Donnellan et al. [26] used C1 laminar screw techniques and obtained ideal postsurgical outcomes. However, multiaxial heads make the fixation difficult because of interference. Also, Zarro et al. [27] in their biomechanical analysis demonstrated that the PASs offered significantly superior resistance to pullout in the axial direction compared with the LMSs. Jin et al. [3] in their morphometric analysis of the $\mathrm{C} 1$ posterior arch demonstrated that $11 \%$ were not suitable for crossing screw placement as the posterior arch was flat and the entry point was on the same side. Thus, we decided to study the feasibility of $\mathrm{C} 1$ crossing PASs in the Indian population which may serve as an ideal alternative or salvage screw when required. Until date, no study that determines the feasibility of this type of screw in the Indian population exists.

According to our study, the mean height of the posterior tubercle was $7.4 \pm 0.8 \mathrm{~mm}$ (range, $5-9.3 \mathrm{~mm}$ ), wherein $84.09 \%$ exceeded $7 \mathrm{~mm}$ compared with $91.51 \%$ in the series by Jin et al. [3]. The average width for the medial part of the VA groove (where the arch transforms into the VA groove) was $5.4 \pm 1 \mathrm{~mm}$ on the right side and $5.8 \pm 1.1 \mathrm{~mm}$ (range, 2.5-8.6 mm) on the left. The width of the middle part was $4.9 \pm 1 \mathrm{~mm}$ (range, $2.5-7.2 \mathrm{~mm}$ ) on the right side and $5.2 \pm 1.1 \mathrm{~mm}$ (range, $2.3-9.8 \mathrm{~mm}$ ) on the left. The width for the posterior tubercle was $5.4 \pm 1.6 \mathrm{~mm}$ (range, 
$2.8-11.8 \mathrm{~mm})$, wherein $88.6 \%(\mathrm{n}=78)$ had a posterior arch width $>3.5 \mathrm{~mm}$. A total of $13.6 \%(\mathrm{n}=12)$ vertebrae were not suitable for screw placement because their posterior arch was thinner than $3.5 \mathrm{~mm}$. Jin et al. [3], the only study before this, measured $64 \mathrm{CT}$ scans and found that the mean value of medial of the VA groove where the arch transforms into the VA groove was $4.70 \pm 0.16 \mathrm{~mm}$ on the left side and $4.62 \pm 0.16 \mathrm{~mm}$ on the right; the width of the middle part between the arch was $4.80 \pm 0.72 \mathrm{~mm}$ (left side) and $4.79 \pm 0.69 \mathrm{~mm}$ (right side); the width of the posterior tubercle was $6.05 \pm 0.71 \mathrm{~mm}$; and $93.40 \%$ of the atlas posterior arches could hold 3.5-mm-diameter multiaxial screws. The mean value of the posterior tubercle height was $7.88 \pm 0.24 \mathrm{~mm}$, in which $91.51 \%$ were $>7 \mathrm{~mm}$, indicating that most of the posterior tubercles could contain two $3.5 \mathrm{~mm}$ crossing screw fixations. When compared, our results were consistent with their results. Doherty and Heggeness [28] measured 88 dried C1 specimens and reported that the width of the posterior arch was $8.0 \pm 2.1 \mathrm{~mm}$. Christensen et al. [29] found that the thickness of the median of the arch was $7.82 \pm 2.64 \mathrm{~mm}$ in 120 C1 specimens and the average height was $9.58 \pm 2.26 \mathrm{~mm}$. These results were same as those of our study, wherein the width of the posterior arch was thicker than $3.5 \mathrm{~mm}$. This finding indicates that the posterior arch could contain one $3.5-\mathrm{mm}$ screw whereas the posterior tubercle was $>7 \mathrm{~mm}$, indicating it could contain two 3.5-mm-diameter multiaxial crossing screws up and down. Moreover, the length of the screw could remain in a safe range, and the mean length of the screws was $16.9 \pm 1.5 \mathrm{~mm}$ on the right side (range, 13.5-20 $\mathrm{mm}$ ) and $16.7 \pm 2 \mathrm{~mm}$ on the left (range, 13-25.4 mm); 75\% ( $n=66)$ of the vertebrae could accommodate $15 \mathrm{~mm}$ or longer screws in their posterior arch. In a study conducted by Jin et al. [3], the mean value was $16.06 \pm 0.57 \mathrm{~mm}$ on the left side and $15.98 \pm 0.56 \mathrm{~mm}$ on the right; $65.57 \%$ of our measurements exceeded $15 \mathrm{~mm}$. Ebraheim et al. [30] studied 50 specimens and showed that the distance from the $\mathrm{C} 1$ posterior arch tubercle to the medial side of the VA groove was $10.4 \pm 1.7 \mathrm{~mm}$ for the male subjects and $8.9 \pm 0.8 \mathrm{~mm}$ for the female subjects. The screw insertion angle also influenced the crossing of trajectories, and it ranged from $11.2^{\circ}$ to $35^{\circ}$ on the right angle and $15.6^{\circ}$ to $38.2^{\circ}$ on the left.

Jin et al. [3] also studied the biomechanical testing of these screws and compared it with that of the $\mathrm{C} 1$ pedicle screws (C1 PS), and they found that C1 PS and PAS systems significantly decreased $\mathrm{C} 1-\mathrm{C} 2$ movement in the intact condition by $55.0 \%$ and $69.6 \%$ in flexion and $53.8 \%$ and $50.4 \%$ in extension, respectively. In axial rotation, the C1 PS and PAS systems significantly reduced flexibility by $86.7 \%$ and $87.8 \%$ in the right axial rotation and $88.3 \%$ and $91.7 \%$ in the left axial rotation, respectively. In lateral bending, there was a trend for the C1 PS and PAS systems toward decreased flexibility compared with the intact condition; however, the C1 PS system decreased the $\mathrm{C} 1-\mathrm{C} 2$ movement in the intact condition by $52.3 \%$ in the left bending and $54.8 \%$ in the right bending, respectively, whereas the PAS system decreased these movements by $33.0 \%$ in the left bending and $24.4 \%$ in the right bending, respectively. Furthermore, no significant difference was detected for the left bending when the PAS system was compared with the C1 PS system, indicating the PAS system could obtain the same stability as the PS.

PAS fixation provides a safe alternative to avoid risk to the VA as well as adequate fixation in patients with a small pedicle of the vertebral arch. It is also a treatment of the dominant side in cases of asymmetrical VAs or the opposite side in cases of unilateral VA occlusion, patients with a large paravertebral venous plexus, and patients with a fracture that extends near the lateral mass or pedicle screw insertion site.

In PAS, the entire screw path can be directly visualized or palpated with the instruments, and this technique seems safe, accessible, and less technically demanding than the other $\mathrm{C} 1$ fixation techniques, though the risk of damage to the dura or spinal cord is still present. Adequate exposure is necessary to avoid such complications and provide accurate screw angle trajectory. Preoperative individual assessment is an essential element to avoid possible complications in $\mathrm{C} 1-\mathrm{C} 2$ fixation techniques.

\section{Conclusions}

The C1 PAS fixation is a feasible method, can be safely practiced, and imposes little risk of injury to the surrounding neural and vascular structures as long as the implants remain intraosseous.

\section{Conflict of Interest}

No potential conflict of interest relevant to this article was reported. 


\section{References}

1. Bisson E, Schiffern A, Daubs MD, Brodke DS, Patel AA. Combined occipital-cervical and atlantoaxial disassociation without neurologic injury: case report and review of the literature. Spine (Phila Pa 1976) 2010;35:E316-21.

2. Nightingale RW, Winkelstein BA, Knaub KE, Richardson WJ, Luck JF, Myers BS. Comparative strengths and structural properties of the upper and lower cervical spine in flexion and extension. J Biomech 2002;35:725-32.

3. Jin GX, Wang H, Li L, Cui SQ, Duan JZ. C1 posterior arch crossing screw fixation for atlantoaxial joint instability. Spine (Phila Pa 1976) 2013;38:E1397-404.

4. Brooks AL, Jenkins EB. Atlanto-axial arthrodesis by the wedge compression method. J Bone Joint Surg Am 1978;60:279-84.

5. Gallie WE. Fractures and dislocations of the cervical spine. Am J Surg 1939;46:495-9.

6. Magerl F, Seemann PS. Stable posterior fusion of the atlas and axis by transarticular screw fixation. In: Kehr P, Weidner A, editors. Cervical spine I. Vienna: Springer; 1987. p. 322-7.

7. Harms J, Melcher RP. Posterior C1-C2 fusion with polyaxial screw and rod fixation. Spine (Phila $\mathrm{Pa}$ 1976) 2001;26:2467-71.

8. Goel A, Laheri V. Plate and screw fixation for atlanto-axial subluxation. Acta Neurochir (Wien) 1994;129:47-53.

9. Huang DG, Hao DJ, He BR, et al. Posterior atlantoaxial fixation: a review of all techniques. Spine J 2015;15:2271-81.

10. Shen K, Deng Z, Yang J, Liu C, Zhang R. Biomechanical study of novel unilateral $\mathrm{C} 1$ posterior arch screws and C2 laminar screws combined with an ipsilateral crossed $\mathrm{C} 1-\mathrm{C} 2$ pedicle screw-rod fixation for atlantoaxial instability. Arch Orthop Trauma Surg 2017;137:1349-55.

11. Yi HJ, Hong JT, Lee JB, et al. Analysis of risk factors for posterior $\mathrm{C} 1$ screw-related complication: a retrospective study of 358 posterior C1 screws. Oper Neurosurg (Hagerstown) 2019;17:509-17.

12. Tessitore E, Bartoli A, Schaller K, Payer M. Accuracy of freehand fluoroscopy-guided placement of $\mathrm{C} 1$ lateral mass and C2 isthmic screws in atlanto-axial instability. Acta Neurochir (Wien) 2011;153:1417-25.
13. Ferguson RL, Tencer AF, Woodard P, Allen BL Jr. Biomechanical comparisons of spinal fracture models and the stabilizing effects of posterior instrumentations. Spine (Phila Pa 1976) 1988;13:453-60.

14. Dickman CA, Sonntag VK. Posterior C1-C2 transarticular screw fixation for atlantoaxial arthrodesis. Neurosurgery 1998;43:275-81.

15. Dickman CA, Sonntag VK. Surgical management of atlantoaxial nonunions. J Neurosurg 1995;83:248-53.

16. Abou Madawi A, Solanki G, Casey AT, Crockard HA. Variation of the groove in the axis vertebra for the vertebral artery: implications for instrumentation. J Bone Joint Surg Br 1997;79:820-3.

17. Kuroki H, Rengachary SS, Goel VK, Holekamp SA, Pitkanen V, Ebraheim NA. Biomechanical comparison of two stabilization techniques of the atlantoaxial joints: transarticular screw fixation versus screw and rod fixation. Neurosurgery 2005;56(1 Suppl):151-9.

18. Melcher RP, Puttlitz CM, Kleinstueck FS, Lotz JC, Harms J, Bradford DS. Biomechanical testing of posterior atlantoaxial fixation techniques. Spine (Phila Pa 1976) 2002;27:2435-40.

19. Naderi S, Crawford NR, Song GS, Sonntag VK, Dickman CA. Biomechanical comparison of C1-C2 posterior fixations: cable, graft, and screw combinations. Spine (Phila Pa 1976) 1998;23:1946-56.

20. Ono Y, Miyakoshi N, Hongo M, et al. Posterior spinal fusion using a unilateral $\mathrm{C} 1$ posterior arch screw and a C2 laminar screw for atlantoaxial fracture dislocation. SAGE Open Med Case Rep 2019;7:2050313X19849276.

21. Aota Y, Honda A, Uesugi M, et al. Vertebral artery injury in C-1 lateral mass screw fixation: case illustration. J Neurosurg Spine 2006;5:554.

22. Rocha R, Safavi-Abbasi S, Reis C, et al. Working area, safety zones, and angles of approach for posterior C-1 lateral mass screw placement: a quantitative anatomical and morphometric evaluation. J Neurosurg Spine 2007;6:247-54.

23. Wright NM. Posterior C2 fixation using bilateral, crossing C2 laminar screws: case series and technical note. J Spinal Disord Tech 2004;17:158-62.

24. Lehman RA Jr, Dmitriev AE, Helgeson MD, Sasso RC, Kuklo TR, Riew KD. Salvage of C2 pedicle and pars screws using the intralaminar technique: a biomechanical analysis. Spine (Phila Pa 1976) 2008;33:960-5. 
25. Floyd T, Grob D. Translaminar screws in the atlas. Spine (Phila Pa 1976) 2000;25:2913-5.

26. Donnellan MB, Sergides IG, Sears WR. Atlantoaxial stabilization using multiaxial C-1 posterior arch screws. J Neurosurg Spine 2008;9:522-7.

27. Zarro CM, Ludwig SC, Hsieh AH, Seal CN, Gelb DE. Biomechanical comparison of the pullout strengths of $\mathrm{C} 1$ lateral mass screws and $\mathrm{C} 1$ posterior arch screws. Spine J 2013;13:1892-6.

28. Doherty BJ, Heggeness MH. The quantitative anatomy of the atlas. Spine (Phila Pa 1976) 1994;19:2497500 .
29. Christensen DM, Eastlack RK, Lynch JJ, Yaszemski MJ, Currier BL. C1 anatomy and dimensions relative to lateral mass screw placement. Spine (Phila Pa 1976) 2007;32:844-8.

30. Ebraheim NA, Xu R, Ahmad M, Heck B. The quantitative anatomy of the vertebral artery groove of the atlas and its relation to the posterior atlantoaxial approach. Spine (Phila Pa 1976) 1998;23:320-3. 